\title{
Empirical Political Theory (Ept): Characteristics, Strength-Weakness, And Challenges
}

\author{
Tonny Dian Effendi \\ Prodi Hubungan Internasional, Universitas Muhammadiyah Malang; Mahasiswa S3 \\ Institute of Political Science, National Sun Yat-Sen University, Taiwan \\ Email: tonny@umm.ac.id
}

\begin{abstract}
This article discusses EPT in political science research in three explanations, namely characteristics, strength-weakness, and challenges. EPT has four critical characteristics, i.e., deductive, empirical, theoretic-methodologist, and replication. EPT, as part of the empiricism approach, covers scientific elements (Hypotetico-Deductive) and theoreticalmethodological elements. It also allows replication., where it can be applied to casecomparison at one theoretical building. However, Formal Model (FM) scholars criticize EPT since it too adopts natural science models. It also depends on the data to prove the relationship or influence between variables in the hypothesis. Nevertheless, the relations do not reflect the causal inference. Nonetheless, EPT contributes significantly to the development of political science research, and replication can be used to build new theories, at least the case comparisons.
\end{abstract}

Keywords: deductive, empirical theory, model, hypothesis

\begin{abstract}
Abstrak
Artikel ini mendiskusikan Empirical Political Theory (EPT) dalam penelitian ilmu politik dalam tiga aspek yaitu akrakteristik, kekuatan-kelemahan dan tantangan. EPT memili empat karakteristik utama yaitu deduktif, empiris, teoritik-metodologis dan replikasi. EPT, sebagai bagian dari pendekatan empirisme, meliputi elemen saintifik (HypoteticoDeductive) dan teoritis-metodologis. EPT juga menerima adanya replikasi sehingga dapat diaplikasikan dalam penelitian perbandingan kasus dalam satu bangunan teori. Meskipun begitu, beberapa ilmuwan pendukung Formal Model (FM) mengkritisi EPT karena terlalu mengadopsi model penelitian ilmu alam. EPT juga tergantung pada data untuk membuktikan hubungan dan pengaruh antar variable dalam hipotesa. Namun, hubungan tersebut tidak merefleksikan makna sebab-akibat. Namun, bagaimanapun juga, EPT berkontribusi besar dalam pembangunan penelitian ilmu politik, dan replikasi dapat digunakan untuk membangun teori baru, setidaknya dalam perbandingan antar kasus.
\end{abstract}

Kata kunci: deduksi, teori empiris, model, hipotesa 


\section{Introduction}

The theory is an abstraction of facts. The theory explains the complex facts in a simple statement so that it is easy to understand. Also, the theory is part of a scientific process in which there are a series of conceptualization activities, generalizations, theorization, and research activities. As a theory, Empirical Political Theory (hereinafter EPT) covers abstraction of political facts, generalization, description of the relationship between concepts, formulation of hypotheses, and series of empirical research activities including data collection and analysis.

I understand the EPT in the four characteristics, namely deductive, empirical, theoretic-methodologist, and replication. According to Karl Popper's argument on the science cycle, EPT should be included in the deductive side since it begins in the theoretical proposition with hypotheses and empirical research test it to verify against the facts. EPT also has empirical characteristics as part of the scientific approach, which, according to Dickinson McGaw and George Watson, the scientific approach is objective, logical, systematic, and aims to describe, explain and predict (Mas'oed, 1990). EPT not only covers theoretical explanations of political facts but includes a series of methods that resulted in a gradual and repetitive process.

Therefore, the EPT also has the methodological part. Moreover, the EPT's research implementation possibly to develops the replication into a cross-case analysis. The researcher can implement the EPT theoretical statement with the same research pattern on different objects during the theoretical conditions fulfilled (object characteristics are relatively equal and data availability).

This paper discusses the EPT in three parts. The first part discusses each of the characteristics of the EPT: (1) the EPT's position in the deductive side of science cycle; (2) the empirical of EPT, including the debate therein especially the opposition of the Formal Model (hereinafter FM) and the idea to combine ETM and FM into Empirical Implications of Theoretical Model (hereinafter EITM) and concluded with examples of EPT, FM and EITM research; (3) EPT as a theory and methodology with the institutionalism theory and cartel theory as example; (4) and the EPT development through the process of replication. The second part explains the EPT strengths and weaknesses as well as the challenge from a new research idea that questioned causal inference in empirical research by a "New Science." The third part is the conclusion of my understanding of EPT. 


\section{Four Characteristics of Empirical Political Theory}

Deductive

We know two logic in a scientific process, i.e., inductive and deductive logic. Walter L. Wallace explains the scientific process in the form of the science cycle which consists of two main activities, the development of theory and implementation of the theory (Mas'oed, 1990). The development of theory is located in the inductive logic side, where it begins from the observation to the fact, categorization into conceptualization, generate relations between concepts, and explanation toward the relations between concepts in a theoretical proposition.

While the implementation of the theory is located in the deductive logic side, where it begins from a theory with its theoretical proposition about the relations between independent and dependent variables in the form of a hypothesis. Empirical research then, verify the hypothesis against the fact to conclude that the theory is valid or not. This empirical research testing called a theoretical falsification test. The more this theory passes the falsification test, the more advanced the science is.
Figure 1. The Science Cycle, an adaptation from Walter $\mathrm{L}$. Wallace, The Logic of Science in Sociology (Aldine, 1971).

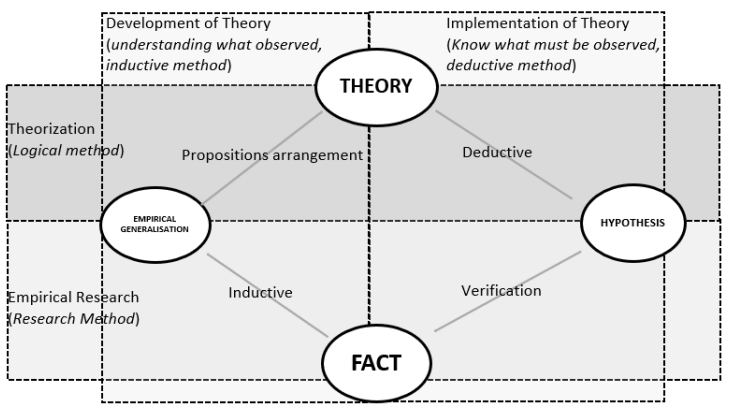

Source: Mohtar Mas'oed, Ilmu Hubungan Internasional: Disiplin dan Metodologi (LP3ES, 1990).

EPT is a theory. What is the theory? McCain and Segal define the theory as a series of statements that consist of basic concepts, relationships between concepts, and theoretical relationships with empirical objects (Mas'oed, 1990). A theory explains the relationship between concepts in the form of hypotheses that can be tested empirically. In this context, the theory contains the three main objectives, describing (represented by the concept), explaining (the relationship between concepts), and predicting (hypotheses). The theory has a crucial feature of deduction. According to Abraham Kaplan (1973), a theory that consists of the deductive logic entered into an axiomatic theory group in which a theory consisted of axioms, statements that functioned as the premise of 
deductive arguments, and theorem, statements derived from The axiom and serves as a conclusion of the deductive argument (Mas'oed, 1990). Therefore, a deductive theory covers a causal relationship in its propositions, which awakens from the axiom group that forms theorem, in one-way direction (causation) that cannot be reversed. That is, the deductive theory encourages the creation of hypotheses that contain causality.

What about the EPT? Is EPT included in the deductive theory? If we include the EPT as a deductive theory, EPT must have the basic concepts, the relationship between the concepts, the explanation of the relationships between concepts that contain causal relationships in the form of hypotheses. According to EPT's supporters, EPT could be involved in the deductive realm. In the discussion of The Scientific Study of Politics, in the book Political Science Research, Kellstedt and Whitten explained that the scientific of political science was done through causal explanation (Kelldstedt \& Whitten, 2018).

They state that the "causal theory" determines the scientific of knowledge in political science, where hypothesized is tested in empirical research. Therefore, there is deductive logic and hypothesis testing in EPT, which called the
"Hypotetico-Deductivism" 2020

HD) logic.

\section{Empirics}

This section discusses the empirical characteristics of the EPT. Johnson, Raynold, and Mycoff (2016) explained that empirical approaches in political science cover observations of empirical facts to build a piece of knowledge, which includes objective observation, experiment and logical reasoning. This process is performed by fulfilling some requirements such as empirical knowledge that must be verifiable, through the process of falsification, objective and logical, transmitted or be transmissible, cumulative, generally applicable, based on empirical facts, contains explanation and parsimony.

The empirical elements in the EPT relate to the hypothesis testing through empirical research. The empirical theory describes the relationship between concepts in this generalization in the form of causality in the hypothesis. Therefore, the concepts are connected, operationalized in the form of research variables (variable dependent and independent). In other words, empirical testing of empirically proven approach is to prove if the hypothesis is whether the variable independent is associated, affects, or causes (changes) in variable Independent. If valid, 
the theory passes the falsification and proven test.

The empirical research is essential for the validity of the theory through hypothesis testing. King, Keohane and Verba (1994) convey that in social science, there are two different empirical research traditions, qualitative and quantitative, but they have the same final goal as logical inference. Scientific research creates the logical inference by following several conditions such as the final goal is inference (descriptive and causal inference), not only just data collection, explicit research method (collection and analysis of data), accessible (accesses for public), uncertain conclusion, and contains a valid set of inference development methods. The King, Keohane and Verba's argument of scientific research in social science called Designing Social Inquiry (hereinafter DSI) which has a significant contribution in explaining the quantitative methods in social and political science research.

However, there are critics toward DSI's application and fundamental argument aspect. In the implementation aspect, Brady and Collier (2010) argue that the use of conventional quantitative methods such as regression and econometrics is less than perfect, and they emphasize on the use of statistical theories to produce more comprehensive analysis.
The statistical theory has a strong empirical tradition that focuses on reasoning the relationship between evidence and inference. Meanwhile, Goertz and Mahoney (2012) reject the argument that qualitative and quantitative research resulted in the logical inference, that being adopted from quantitative methods and statistics perspective. They argue that qualitative and quantitative have different cultures (types of data, practice, collection and analyzing data, generating conclusions). Goertz and Mahoney find 25 differences between qualitative and quantitative and the mix-method becomes the best solution to bridge those differences.

Nevertheless, Goertz and Mahoney agree that both qualitative and quantitative use of mathematical language in different ways. Qualitative use of mathematics in the context of logic and set theory, while quantitatively use mathematics as a tool by using the theory of statistic and probability. Therefore, empirical research covers both qualitative and quantitative traditions. However, EPT has a strong association with mathematical language or numbers because empiricism needs the logical reason where the statistical theories can prove it. It becomes visible when people view the EPT is close to a quantitative approach because of the number and mathematical language because they view the difference between 
qualitative and quantitative on the difference between a word and a number.

The use of natural science research methods in social sciences, as a scientific method, is not without opposition. Some other political scholars oppose this opinion and argue that social and political science does not need to follow the natural science's method to becomes scientific because natural and social sciences have different research objects. Clarke and Primo (2012), even mentioned that the efforts of some political science scholars were attempting to apply HD logic in political science research as a "physic envy," an action based on the envy to natural science achievements, then trying to adapt it to political science.

Clarke and Primo have two main arguments on their critic toward EPT. First, social sciences already have a model that can explain the social phenomenon and political facts. This model can function as a theory because it also contains the assumption of causal relationships (a proposition if in theory). Therefore, the model is the best way to explain social phenomena and political facts because social science research objects are human behavior that researchers cannot be conditioning them in particular situations like laboratory experiments in natural sciences. Second, the EPT focuses on empirical research, hypothesis testing and theory falsification, while the model focuses on explanation on the social phenomenon and political facts. Clarke and Primo argue that empirical research is only used for the sake of theory itself in the falsification test, while models have broader uses because of simplifying the phenomenon without having to prove it through hypotheses tests. In other words, a model is enough to explain the social phenomenon and political facts without having to use empirical research. This idea refers to the foundation of the Formal Model (hereinafter FM).

Does EPT not cover the model? Kellstedt and Whitten argue that models are part of the theory to construct relationships between variables that form hypotheses, while Clarke and Primo argue that the model is used to explain the phenomenon without having to the hypothesis test. However, they have a similar argument in the development of models, but they have different views on the model's function. Political scientists try to explain political facts in a simple statement. They categorize facts into some groups to form concepts and then generalize them to get the relationship between the concepts that make up a model. To this stage, there is no different opinion between EPT dan FM. Disagreements began in the next steps, where Kellstedt and 
Whitten argued that the model helped the theory to form the hypothesis that is verified into empirical research. Meanwhile, Clarke and Primo argue that the next process is precisely going back to the fact because the model can directly explain facts through assumptions without going through the theory and the hypotheses.

Figure 2. The position of Model by Kellsted \& Whitten and Model by Clarke and Primo in Knowledge Circle

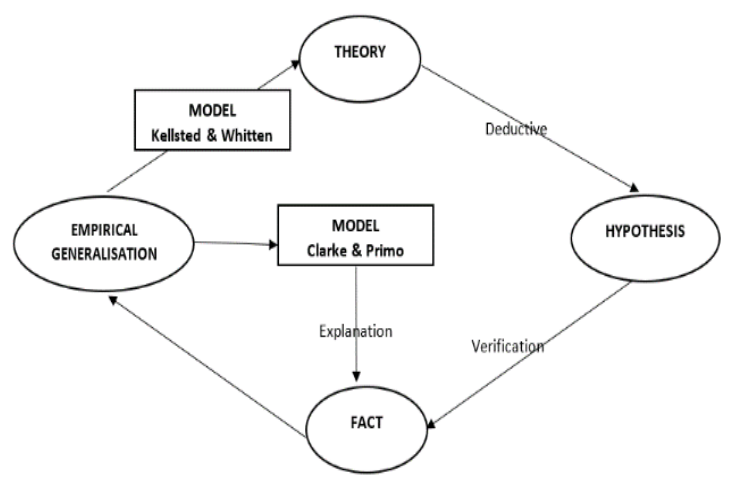

Before Clarke and Primo discussed the model-based approach in political science, Morris P. Fiorina, in 1975, had discussed the model in political science (Fiorina, 1975). Fiorina argues that the social phenomenon and political facts create a model by simplifying them into simple assumptions. The model is neutral and contains predictions about the possibilities occurring in a phenomenon or reality. In other words, the model also has a theoretical element, called prediction. Fiorina accommodated Milton Friedman's opinion that the model has such predictive power in theory so that the model also has two theory criteria i.e., explanation and prediction (Fiorina, 1975). However, Fiorina also explains the possibility of subjectivity in the model because the model was built based on the limited researcher's knowledge and assumption on the object.

Clarke and Primo and Fiorina explain the model's power prediction differently. Although they agreed that the researcher's assumption develops model, Clarke \& Primo emphasize the similarity aspect or similarities between models and reality. In the process of simplification of research objects, researchers make an analogy and create a model. Meanwhile, Fiorina explains this assumption process more complicated by presenting a stage ranging from simplifying reality through primitive concepts, then becoming a more complex concept and ending to assumptions.

Fiorina's significant contribution to FM is the use of mathematical formulas. Mathematical formulae make researchers easier to explain political facts such as political processes and behavior in several possibilities. Fiorina uses a mathematical formula to explain political behavior in the legislative decision-making process. It looks like game theory. According to Alan Isaak, political science and international 
relations have almost no model, except game theory (Mas'oed, 1990). Models in political science and international relations are kinds of theories that have not been tested or it cannot be tested, abstract, using an ideal concept and represented by numbers. A model contains a fundamental concept definition, assumptions about concepts and relationships between concepts, statements of relationships between concepts, model logic, and the possibilities that occur. Therefore, models in political science are more in the form of game theory with a variety of variants where its use uses logic possibilities and is represented by numbers.

Figure 3. Development of model and its prediction power by Fiorina and Clarke \& Primo

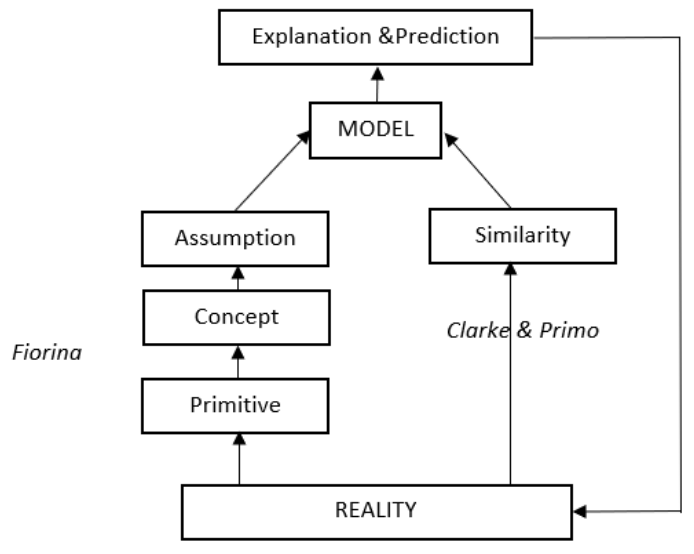

The debates between EPT and FM stays on the use of empirical research and assumption to explain social phenomena and political facts. Granato \& Scioli (2004) argue that both EPT and FM have imitations. EPT limited in the implementation, where the case study (qualitative) has weaknesses in the context of weak conclusions, while statistics (quantitative) focus more on hypothesis testing than describing the phenomenon. Meanwhile, FM has a weakness in the context of the empirical proving because it is based solely on the assumption. In other words, FM is less empirical, while EPT is too theoretical.

The journal of Political Analysis in 2003 published a special issue to discuss possible combinations between EPT and FM, the Empirical Implication of Theoretical Models (EITM) (Alfridch \& Alt, 2003). EITM seeks to combine EPT and FM (Granato et al., 2015). FM provides explanations and predictions toward social phenomena and political facts that sometimes also use mathematical language, but it less empiric. While EPT has a case study and statistic method that is used to prove hypotheses, both are combined where FM provides models to create premises and then equipped with a case study or statistic in ETP to produce a logical conclusion (based on FM assumptions) which supported by empirical research and data (based on EPT). Therefore, EITM focuses on the used model as the intersection between FM and EPT. 
Table 1. Formal Model, Empirical

Political Theory and EITM

\begin{tabular}{|l|l|l|l|}
\hline & Formal Model & $\begin{array}{l}\text { Empirical Political } \\
\text { Theory }\end{array}$ & EITM \\
\hline Logic & Inductive & Deductive & Inductive-deductive \\
\hline Foundation & Based on assumption & Based on theory & $\begin{array}{l}\text { Based on assumption and } \\
\text { theory }\end{array}$ \\
\hline Focus & $\begin{array}{l}\text { Focus on how model } \\
\text { describe } \\
\text { phenomenaffact }\end{array}$ & $\begin{array}{l}\text { Focus on the hypothesis } \\
\text { test }\end{array}$ & $\begin{array}{l}\text { Focus on both model and } \\
\text { hypothesis }\end{array}$ \\
\hline Weakness & Less empirical & Too theoretical & $\begin{array}{l}\text { Challenging to combine or } \\
\text { mix between FM and EPT }\end{array}$ \\
\hline Implementation & Game Theory & $\begin{array}{l}\text { Case study (qualitative) } \\
\text { Statistical (quantitative) }\end{array}$ & $\begin{array}{l}\text { Game theory+Quantal } \\
\text { Response Equilibrium } \\
\text { (QRE) } \\
\text { Formal model+Philips } \\
\text { curve } \\
\text { Marcov Chain Model }\end{array}$ \\
\hline
\end{tabular}

Source: Processed from Granato \& Scioly (2004)

Three research below explains the differences between FM, EPT and EITM. They are research on game theory in the democratization process in Hongkong (Wong, 2016), state's voting behavior in the UN General Assembly (Voeten, 2000) and empirical testing of the calculus voting (Blais, Ying, and Lapp, 2000).

Mathew Y.H. Wong analyzed negotiations between Beijing and Hong Kong in the process of democratization. Wong argued that the strength of civil society in Hong Kong influenced Beijing's choice of policy towards Hong Kong. The game-theory model explains this negotiation with the policy's options and its payoffs. This research is an example of FM because the assumption that Beijing considers the power of the civil society in Hong Kong is described in policy options with the mathematical language and the calculation on the payoff. Wong does not provide empirical data analysis to prove the assumption.

Meanwhile, Voeten conducts the state's voting behavioral research of postCold War countries by analyzing the voting behavior in the UN General Assembly. Voeten examines the hypothesis of several theories in international relations study by seeking the relationship between the main determinants factor in each theory (variable independent) to the behavior of state voting in the UN General Assembly (variable dependent). To examine the hypothesis of each theory, Voeten uses a spatial model with the state's voting empirical data in the UN General Assembly.

The results of Voeten's research show that the behavior of cold postwar countries is relatively stable and plays in one dimension. Voeten's research is an EPT because it tests the hypothesis by empirical research on empirical data. The third study is research on voters' behavior with the rational choice model described in the formula $\mathrm{R}=\mathrm{BP}-\mathrm{C}$ where $\mathrm{R}$ is the reward for voting, $\mathrm{B}$ is the profit for voting, $\mathrm{P}$ is the probability, and $\mathrm{C}$ is the cost for voting. Blais, Young and Lapp surveyed the referendum in Quebec in 1995 and British Columbia in 1996 for the empirical test of the rational choice model. The empirical test result of this model indicates that the 
rational choice model has a weakness in explaining the behavior of voting because it does not accommodate other variables such as duty. This third study is an example of the EITM, where researchers conducted empirical tests, through survey data and regression analysis, on the rational choice model.

\section{Theoretic-Methodologist}

Empirical Political Theory (EPT) is not only a theory, but it also consists of the methodological element. EPT has not only the theoretical side, the proposition of the relationship between variables, but also contains a series of processes that must be met or performed in the application of the theory. To discuss the theoretical and methodological side of the EPT, we can use the institutionalism theory as an example.

The institutionalism theory argues that an institution influences the individual's behavior. North (1991) explains that humans create institutions to govern relationships between individuals through a set of formal and informal rules. By using analysis on the trade revolution, North argues that based on economic logic in game theory, when a game has a slight number of players, repeated game patterns, and institutions provide enough information between players, individuals will work together to maximize their goal.
Conversely, when the game patterns change or even stop, players are getting more, the cooperation will be difficult to achieve. The world trade history shows the evolution from a simple model of barter to the world trade institution, indicating that each of the actors involved in it underwent change and evolution in the trading institution. This evolution causes stability and change. That is, the institution is not static but dynamic. North has two essential arguments. First, the institution has a set of rules, frameworks, values, guidelines, habits and traditions used to govern the individuals. Second, the institution is dynamic and has a repeating game pattern that causes stability in the institution, although there is also a possibility of change.

New institutionalism covers the dynamic institution idea. New institutionalism covers three different groups, namely the historical, rational choice, and sociological institutionalism (Hall \& Taylor, 1996). Historical institutionalism is a pivotal group among rational choice and sociological because it contains two approaches at once, calculus and cultural approach.

The calculus approach suggests that every individual or actor is always strategizing to achieve its interest by minimizing losses, while the institutions provide information to actors and regulate 
their behavior with a set of rules. According to this approach, stability in the institution is achieved due to the creation of the Nashequilibrium. Meanwhile, the cultural approach argues that each individual follows the patterns and habits in institutions as a routine and institutions govern individual behavior by providing a cognitive framework and a series of values and morality. Institution achieves stability through collective behavior and individual bounded in constructed identity.

The rational choice institutionalism emphasizes on the calculus approach by arguing that individual behaviors are determined by the calculations in their strategies to achieve interests and institutions structures manage the interaction between individual strategies. Sociological institutionalism emphasizes the cultural approach, where culture (symbol, cognitive frameworks and moral templates) becomes the institution itself. Culture manages individual behavior in a united collective identity and behavior.

Historical institutional has the role of provides the foundation of institutional arguments, while rational choice and sociological role explain institution in a different direction. Rational choice provides tools to analyze the relationship between the institution and individual behavior, while sociological gives an understanding of individual behavior influenced by identity and collectivity in institutions.

Historical, rational choice, and sociological institutions explain the theoretical side of the institutionalism theory. They explain the basic arguments or models; the institution affects the behavior of individuals. As an empirical theory, the hypothesis is that the institution (variable independent) determines individual behavior (variable dependent). Rational Choice explains the relationship among variables as the influence of institutional structures on rational calculations on individual strategies within the context of the institution, while sociological provides explanations in the form of a series of rules, values and cognitive frameworks that influence individual behavior in collectivity.

Meanwhile, institutionalism also contains methodological elements inside. Daniel Diermeier and Keith Krehbiel (2003) argue that institutionalism is more self-indicating as a method than theory. Some research in institutionalism shows stable results, and most of them cover a comparison of the collective choice between behavior and outcomes. According to Diermeier and Krehbiel, the institutionalism theory contains a theoretical relationship between 
institutions, behaviors and outcomes where previous studies demonstrated the stability of behavioral patterns in institutions based on the collective choice process. On the other hand, this theory also contains set of research method that is divided into four steps as defining behavioral postulate of political actors in the collective choice setting, determining the character of the institutional effect, conducting empirical tests on behavior in institutional settings and search for outcomes, and compare these implications to empirical regularities and data. The first and second step relates to the assumptions and arguments of the theory, while the third and fourth phases relate to the implications of the theory. Diermeier and Krehbiel argue that this process is iterative from the fourth stage back to the second stage when it is possible to find a difference in results or at different institutions so that it affects changes in behavioral postulate in the second step.

This iterative brings three consequences. Firstly, the theory of institutionalism is not only a theory but also a research method of the institution itself. Secondly, the iterative process develops institutional theory, even creates new theory, the theory of institutionalism. Thirdly, the implementation of institutionalism theory in many cases possibly brings replication and create a comparative study. The next section discusses the replication of institutionalism theory research, called the cartel theory.

\section{Replication}

The EPT, in the case of institutionalism theory, applies to different cases or institutions. It refers to Johnson, Raynold, and Mycoff's (2016) description of the empirical approach that one of its characteristics is transmissible and generally applicable (can be applied in different cases). Cartel theory in legislative institution discussion is proof of the replication character from EPT.

Cartel theory argues that there is a group like to control the legislative agenda. This theory has evolved in politics of the United States where the political party and its faction play in selecting and submitting the policy proposed to the Committee, and the Committee will decide the plan to be carried in the plenary session, and the latter will be voted on the draft of the policy (Cox, Masuyama \& McCubbins, 2000).

Based on the game pattern above, it was argued that the government (ruling party) monopolized the agenda-setting (those who submitted the policy draft on the agreement of government parties and factions therein, cartel agenda). The government and its faction have complete information about the preferences of all 
parties and their faction, and they will use the draft policy as a negotiation tool to change the outcome of the game.

Gary W. Cox and Mathew D. McCubbins are central figures in this cartel theory, where they then try to apply theories derived from observations of legislation politics in the United States to other countries with the parliamentary system (Jones \& Hwang, 2005). The research on cartel theory in Japan (Cox, Masuyama \& McCubbins, 2000), Brazil (Neto, Cox \& McCubbins, 2002), Germany (Chandler, Cox \& McCubbins, 2008), Italy (Cox, Heller, \& McCubbins, 2008), Israel (Akirav, Cox \& McCubbins, 2010), European countries Central and Eastern (Zubek, 2011), Chile (Toro-Maureira \& Hurtado, 2016), Poland (Nalepa, 2016; 2017) show that there is a group that dominates the political legislation in parliament that control and set the policy agenda.

The implementation of Cartel theory in countries outside the United States suggests that EPT can be replicated. EPT can be applied to many cases in different countries, which means that this theory has general explanatory and transmissible. This situation makes the EPT have the opportunity to cross-case analysis and develop or establish a new theory.
EPT: Strengths, Weaknesses, and

\section{Challenge}

After understanding the four characters of the EPT, deductive, empirical, theoreticmethodologic, and replication, this section discusses the strengths and weaknesses of the EPT. Besides, this section also discusses the challenges of today's contemporary research, where advanced technology helps much research alongside large data availability, the big data.

The EPT has some strengths:

1. EPT is scientific because it is based on deductive logic (HD) and is evidenced by empirical research. EPT has passed the falsification test where EPT is evidenced by the real data (empiric); therefore, the EPT argument can be held accountable for its truthfulness. Another implication of the EPT scientific character is that the EPT contains a qualitative and quantitative approach, depending on the object and data availability. In other words, EPT can use small N-data (qualitative) and large $\mathrm{N}$-data (quantitative).

2. EPT is theoretical-methodologic. EPT is not only contained theoretical elements that are statements or propositions that explain the relationship between the 
concept (variable independentdependent) but in its hypothesized through empirical research, the EPT contains a methodology element that is the steps or research process (determining postulate, character, empirical proving and comparative outcomes), particularly in the institutionalism theory.

3. EPT has cross-case analysis and replication capabilities. In the case of Cartel theory, the EPT has transmissibility or can be replicated in similar cases in different places or countries. Nevertheless, the EPT can be categorized into middlerange theory groups, which are theories that combine theory and empirical research and have a medium-range with limited explanation (Masoed, 1990). That is, replication at the EPT is also limited to similar cases, and its exposes based on the scope of the theory itself.

4. EPT has the ability in the theoretical building. EPT has a replication power that can be used to compare various cases in many countries, so it is very likely to build an enriching theory that already exists or build a new theory (like the case theory of institutions and institutions theory) or in the context of comparative politics.

5. In the context of the relationship with FM, EPT has the opportunity to complement FM, which lacks a theoretical explanation, by using empirical research to complement the model filed by FM. That is, the EPT is likely to combine with FM (EITM).

Meanwhile, EPT also has some weaknesses:

1. Because it embraces empiricism approach, as does the criticism of FM supporters, EPT's empirical nature contains some weaknesses such as over imposing methods of natural science research to social sciences and focus to theory testing rather than explanation the fact itself.

2. Due to the empirical approach is based on the verification of facts or data, the EPT is highly dependent upon the availability of empirical data for hypotheses testing. That is, the EPT will be hard to explain or verify when data is unavailable.

3. EPT contains the relationship between the variables formulated in the hypothesis, where the researcher's understanding and assumption strongly influence the 
variable construction. Therefore, although it uses empirical methods in proving the theory, the problem is precise to postulates in theory which may be subjective researchers that can be influenced by various factors.

4. The researchers have limitations in drafting and using the language of mathematics to develop a theoretical model. EPT should be able to reach all the traditions of both qualitative and quantitative research methods. However, in the implementation, EPT uses quantitative methods due to statistic (large $\mathrm{N}$-data) than case studies (small $\mathrm{N}$-data) in qualitative tradition.

5. EPT proves the relationship between variables, but relative does not explain the causal inference between variables themselves. Although it uses a statistical approach in the hypotheses, the analysis only concluded that the variable independent relates or affects the variable dependent, and then the theory is correct.

Concerning the fourth weakness, there is a challenge to EPT in current empirical research development. Judea Pearl and Dana Mackenzie wrote a book on
The Book of Why and posed a scientific revolution idea of New Science (Pearl \& Mackenzie, 2018).

This New Science idea originated from criticism of the scientific method, including the empirical approach, which mainly has not touched on causality. Whereas causality elements, in the form of the question "Why" is a fundamental element in science. Pearl proposes a concept of Ladder of Causation in explaining the current scientific process that is divided into three phases, namely association, intervention, and counterfactual. Unlike empirical research that aims to describe, explain and predict, Ladder of Causation emphasizes observation, prediction and understanding. Pearl criticizes today's empirical research that still at the association stage to see the regularities in observation.

To reach the counterfactual stage with the main activity of imagining, researchers should think about causality "whether the independent variable causes dependent variable?" not "whether the independent variable relates or affects the dependent variable? ". Pearl explained the change in this science as New Science as the result of the Causal Revolution, a new system in the cause-effect relationship by using the mathematical language of the causation logic. Returning to the EPT, 
Pearl' s Causal Revolution gave the challenge to political scientists to rethink whether empirical research in the EPT has explained causality (to answer why questions) or still at the bottom of the ladder of Causation?

\section{Conclusion}

Finally, Empirical Political Theory (EPT) is a political theory that used a scientific and empirical approach. Scientific means it follows the hypotheticodeductivism (HD) logic, while empirical means it proved by empirical data. EPT has the hypothesis that consists of the relations between the independent variable and the dependent variable, which will be tested by empirical research. As an empirical theory, EPT aims to describe, explain, and predict. Therefore, the EPT has four main characteristics, namely deductive (hypothesis test), empirical (following empirical rules: objective, measurable, based on fact or data), theoreticmethodology (consist both theoretical and methodological elements), and replication (can be replicated and possibly for theoretical building).

The EPT covers qualitative (case study) and quantitative (statistical) culture. Although the EPT looks closer to a quantitative approach with statistical theory and the use of mathematical language, empirical elements in the EPT can also be achieved with qualitative research. In other words, EPT can be done with a quantitative and qualitative approach by fulfilling scientific research rules. Also, EPT is useful to respond to the big data in domestic and international politics today and makes researchers easier to conduct research. Nevertheless, the challenge of the current EPT is whether this theory has explained the causality of the relationship therein.

\section{References:}

Akirav, O., Co, G.w., and McCubbins, M.D. 2010. Agenda Control in the Israeli Knesset during Ariel Sharon's Second Government. The Journal of Legislative Studies. 16(2). 251-267

Aldrich, J., and Alt, J. 2003. Introduction to the Special Issue. Political Analysis. 11(4). 309-315

Blais, A., Young, R., and Lapp, M., 2000. The calculus of voting: An empirical test. European Journal of Political Research. 37(2).181-201

Brady, H. E., and Collier. D. (eds). 2010. Rethinking Social Inquiry: Diverse Tools, Shared Standard. Plymouth: Rowman \& Littlefield Publishers Candler, W. M., Cox, G. W., and McCubbins, M. D. 2006. Agenda 
Control in the Bundestag, 19802002. German Politics. 15(1). 27282

Clarke, K.A., and Primo, D.M., 2007. Modernizing political science: A model-based approach. Perspectives on Politics. 5(4).741753.

Clarke, K.A., and Primo, D.M., 2012. A model discipline: Political science and the logic of representations. Oxford University Press.

Cox, G. W., Cox, G. W., Masuyama, M., Masuyama, M., McCubbins, M. D., \& McCubbins, M. D. (2000). Agenda Power in the Japanese House of Representatives. Japanese Journal of Political Science. 1(1). $1-21$.

Cox, G.W., Heller, W. B., and McCubbins, M.D. 2008. Agenda Power in the Italian Chamber of Deputies, 19882000. Legislative Studies Quarterly. 33(2). 171-198

Diermeier, D., and Krehbiel, K., 2003. Institutionalism as a Methodology. Journal of theoretical politics. 15(2).123-144.

Fiorina, M. P., 1975. Formal Model in Political Science. American Journal of Political Science. 19(1). 133-159 Goertz, G., and Mahoney, J. 2012. A Tale of Two Cultures: Qualitative and
Quantitative Research in the Social Sciences. New Jersey: Princeton University Press

Granato, J., and Scioli, F., 2004. Puzzles, Proverbs and Omega Matrices: The Scientific and Social Significance of Empirical Implication of Theoretical Model (EITM). Perspective on Politics 2. 313-323

Granato, J. et al., 2015. EITM: An assessment with an application to economic voting. Electoral Studies. 40. 372-393

Hall, P.A., and Taylor, R.C., 1996. Political science and the three new institutionalism. Political studies. 44(5). 936-957

Johnson, J. B., Reynolds, H.T. and Mycoff, J.D. 2016. Political Science Research Methods. California: CQ Press

Jones, M. P., and Hwang, W. 2005. Party Government in Presidential Democracies: Extending Cartel Theory Beyond the U.S. Congress. American Journal of Political Science. 49(2). 267-282

Kaplan, A., 1973. The Conduct of Inquiry: Methodology for Behavioral Science. New Brunswick: Transaction Publisher

Kellstedt, P. M., and Whitten, G. D., 2018. The Fundamental of Political 
Science Research. Cambridge: Cambridge University Press

King, G., Keohane, R.O., and Verba, S. 1994. Designing Social Inquiry: Scientific Inference in Qualitative Research. New Jersey: Princeton University Press

Mas'oed, M., 1990. Ilmu Hubungan Internasional: Disiplin dan Metodologi. Jakarta: LP3ES

Nalepa, M. 2016. Party Institutionalization and Legislative Organization: The Evolution of Agenda Power in the Polish Parliament. Comparative Politics. 83(3). 353-372

Nalepa, M. 2017. Adapting Legislative Agenda Setting Models to Parliamentary Regimes: Evidence from the Polish Parliament. Studies in Logic, Grammar and Rhetoric. 50(1). 181-203

Neto, O. A., Cox, G.W., and McCubbins, M.D. 2002. Agenda Power in Brazil's Camara dos Deputados, 1989-98. World Politics. 55(4). $550-578$

North, D.C., 1991. Institutions. Journal of economic perspectives. 5(1).97-112

Pearl, J., and Mackenzie, D. 2018. The Book of Why: The New Science of Causal and Effect. New York: Basic Books
Toro-Maureira, S. and Hurtado, N. 2016. The Executrive on The Battlefield: Government Amandments and Cartel Theory in the Chilean Congress. The Journal of Legislative Studies. 22(2). 196-215 Voeton, E., 2000. Clashes in the Assembly. International Organization. 54(2). 185-215.

Wong, M. Y. H., 2016. A Game-Theory Model of Democratization and Political Reform in Hong Kong. Taiwan Journal of Democracy, 12(2). 127-154

Zubek, R., 2011. Negative Agenda Control and Executive-Legislative Relations in East Central Europe, 1997-2008. The Journal of Legislative Studies. 17(2). 172-192 